\title{
COVID-19: Survey on Awareness Level and Psychological Status During the Outbreak
}

\author{
IJCRR \\ Section: Healthcare \\ Sci. Journal Impact \\ Factor: 6.1 (2018) \\ ICV: 90.90 (2018) \\ (c) (i) (8) \\ Copyright@IJCRR
}

Vaishnavi P. ${ }^{1}$, S. Ramkumar ${ }^{2}$

'Research Scholar, Department of Management Studies, Hindustan College of Arts and science-Coimbatore, India; ${ }^{2}$ Professor, Department of Management Studies, Hindustan College of Arts and science-Coimbatore, India.

\section{ABSTRACT}

Background: Research information is required to create evidence-driven methodologies to decrease unfavourable mental impacts and psychiatric side effects amid the pandemic situation. Objective: This survey aimed to discover awareness level, behaviour, attitudes and also to analyze the psychological status related to coronavirus outbreak.

Methods: The online survey was conducted by snowball examining methods.

Results: This study included 520 respondents from different cities of Tamilnadu. $71 \%$ of the members are aware of the preventive measures. $48 \%$ of the members are with high fear and uneasiness since of this widespread circumstance in Tamilnadu. $52 \%$ of the members feel boredom, frustrated since of lost their open-air exercises. $72 \%$ of the participants feel a change of mood and behaviour. There is a positive correlation between change in sleep and eating pattern and time saved.

Conclusion: During the various stage of COVID-19 episode in Tamilnadu the results are compared to the existing COVID-19 widespread outbreak; they gain access to awareness level, fear, emotional distress, as the affected persons are viewed as moderate. It is very important to take care of the mental welfare of the population and proactive steps to play down its inconvenient impacts amid the COVID-19 pandemic.

Key Words: COVID-19, Coronavirus, Awareness Level, Psychological Impact, Stress, Depression.

\section{INTRODUCTION}

Corona Virus is a tremendous family of infections that are known to cause sickness extending from the common cold to more serious infections such as Serious Intense Respiratory Disorder (SARS). A novel corona infection (COVID-19) was recognized in 2019 in Wuhan, China. This can be a new infection that has not been once in the past recognized in people. In January 2020 the World Health Organization (WHO) announced the flare-up of a new coronavirus disease, COVID-19, to be a public health crisis of worldwide concern. WHO expressed that there's a high hazard of COVID-19 spreading to other nations around the world. In Walk 2020, WHO evaluated that COVID-19 can be characterized as widespread. ${ }^{4}$ An outbreak of a worldwide epidemic causes panic and anxiety among numerous and allegedly impacts the psychological well-being of each person. The lives of contaminated people, family and companions, and the society are at hazard due to the propagated conceivable impacts of the 2019 novel coronavirus (COVID-19). The infection shows up to spread using human to human transmission in a comparable design to flu and a few infections causing upper respiratory diseases, i.e., through contact with discharges from infected individuals. ${ }^{1}$

The infection overwhelmingly replicates within the respiratory system amid the prodromal period, which advance contributes to the transmission of the infection as patients may still be having the disease within the absence of symptoms. After the introductory reports of contamination, in the following weeks. Universally, there are 3,021,049 disease cases detailed as of April 27, 2020, with 27,787 new diseases whereas cases detailed of COVID-2019. The current death rate is at 208,527globally of as of April 27, 2020. This is shown in figure $1 .{ }^{14}$

This virus is additionally known to be transmitted by gently sick or pre-symptomatic tainted people, which posture a challenge to control compared to the Center East respiratory

\section{Corresponding Author:}

Vaishnavi P., Research Scholar, Department of Management Studies, Hindustan College of Arts and science-Coimbatore, India. Email: vaishnavipalanisamy@gmail.com

ISSN: 2231-2196 (Print)

Received: 16.06 .2020
ISSN: $0975-5241$ (Online)

Revised: 23.07 .2020
Accepted: 28.08 .2020
Published: 22.09 .2020 
disorder (MERS) and SARS pandemics. Whereas the scientific community and the WHO is still working on numerous unanswered viewpoints of this outbreak, clinicians and the common public are reacting to this dubious circumstance based on the limited affirmed data. ${ }^{3}$

WHO announced that the most common symptoms of COVID-19 are fever, dry cough, and fatigue. Other symptoms that are less common and may affect some patients include aches and pains, nasal congestion, headache, loss of taste or smell or a rash on the skin. These symptoms are usually mild and begin gradually. Some people become infected but only have very mild symptoms. The infection overwhelmingly replicates within the respiratory system amid the prodromal period, which advance contributes to the transmission of the infection as patients may still be having the disease within the absence of symptoms. ${ }^{15}$

Mostly $80 \%$ of individuals affected in India don't show any symptoms. This uncertain circumstance has as of now made a huge extent of unsettling impacts within the lives of people over the world, which calls for the study to think about its proposal on the psychological wellbeing based on the studies of the past outbreak. The COVID-19 outbreak influences all sections of the population and is especially negative to individuals of those social groups within the most helpless circumstances; proceed to influence populations, including individuals living in poverty circumstances, older people, and people with inabilities, youth, and indigenous people groups. Early evidence shows that the wellbeing and financial impacts of the virus are being borne excessively by destitute individuals. ${ }^{4}$ Individuals without access to water, refugees, transients, or displaced people also stand to endure excessively both from the widespread and its consequence - whether due to limited development, fewer business openings, expanded xenophobia etc. In case not appropriately addressed through an arrangement, the social emergency made by the COVID-19 widespread may too increment inequality, exclusion, separation and worldwide unemployment in the medium and long term. Comprehensive, widespread social security frameworks, when in place, play a much strong part in protecting labourers and in reducing the prevalence of poverty, since they act as programmed stabilizers. That's, they give essential income security at all times, in this manner upgrading people's capacity to manage and overcome shocks. Innate peoples are especially vulnerable at this time due to significantly higher rates of communicable and non-communicable illnesses, need of access to basic services, absence of socially appropriate healthcare, and in case any, under-equipped and under-staffed nearby medical offices. Since its onset, the COVID-19 widespread has spread to nearly all nations of the world. Social and physical distancing measures, lockdowns of businesses, schools and overall social life, which have become commonplace to reduce the spread of the in- fection; have also disturbed numerous normal aspects of life, including sport and physical activity. ${ }^{6}$

The raging pandemic unleashed by profoundly infectious COVID-19 virus - has activated uncommon confinements not only on the way of life of individuals but moreover on an extension of financial activities, and the declaration of national crises in most nations around the world. Developing demand for critical healthcare and rising death rates are straining national healthcare frameworks. The widespread is disturbing worldwide supply chains and international trade. With about 100 nations closing national borders during the past month, the development of individuals and tourism flows have come to a shrieking halt. Millions of labourers in these nations are confronting the distressing prospect of losing their jobs. ${ }^{7}$ Governments are considering and rolling out expansive stimulus packages to turn away a sharp downturn of their economies which may dive the worldwide economy into a profound retreat. Fears of the exponential spread of the virus - and developing instabilities around the adequacy of different control measures have rocked.

The current COVID-19 widespread is causing far-reaching concern, depression and anxiety among individuals all over the world. As per the World Health Organisation, it has initiated a significant degree of fear, stress and concern within the population. In public psychological wellbeing terms, the most mental effect such as rates of stress or anxiety has been raised. With the presentation of new impacts - particularly quarantine, numerous people's normal activities, schedules or employments confronting terrible impact. ${ }^{2}$ Millions of lives have been intensely influenced by a few psychological changes such as expanded levels of loneliness, depression, sedate use, and self-harm or self-destructive behaviour and demanding stress-coping-adjustment process is ongoing. Furthermore, myths and deception almost this plague, journey bans and official orders to isolate travellers might influence the public's mental wellbeing. This may impact people's quality of life and psychological wellbeing. ${ }^{5}$

\section{COVID 19 in India}

The first case of the 2019-20 corona infection widespread in India was detailed on 30 January 2020, starting from China. As of 27 April 2020, the Ministry of Health and Family Welfare has affirmed an add up of 28,380 cases, 144 recuperations (counting 1 migration) and 894 passing within the country. ${ }^{14}$ Specialists propose the number of contaminations can be a considerable underestimate, as India's testing rates are among the least within the world. The contamination rate of COVID-19 in India is detailed to be 1.7, essentially lower than within the most exceedingly bad affected nations. The COVID-19 infection rate in India remains low relative to population size. The COVID-19 fatality rate in India is 2.87 per cent, the lowest among countries badly hit by the pandemic. 
Government of India is taking all essential steps to guarantee that we are arranged well to confront the challenge and danger postured by the developing widespread of COVID 19 - the Crown Infection. With the dynamic support of the individuals of India, we have been able to contain the increase of the virus in our nation. The foremost imperative calculates in avoiding the spread of the virus locally is to empower the citizens with the correct data and taking safety measures as per the advisories being issued by the Ministry of Health and Family Welfare. In India, the coronavirus cases have raised, with health service affirming 28,380 positive cases so far. 894 individuals have died due to the coronavirus, as per the government. India has detailed 6,523 cured cases in novel coronavirus. $^{15}$

The nation saw its single greatest bounce from April 2, with Delhi's Markaz Nizamuddin devout gathering contributing most of the cases. India is forcing one of the world's biggest lockdown, inquiring individuals to remain domestic and support social distancing. The point of the lockdown is to cut the conceivable human to human transmission and diminish the number of cases. These are as well early days to judge the effect of the lockdown but might still play out by making a difference in diminishing number of cases. ${ }^{14}$ The Bacillus Calmette-Guerin (BCG) antibody is presently examined as a conceivable reason for moo COVID-19 cases in India. The antibody is all around managed in India to secure against tuberculosis. Researchers in the US, Europe and Australia have begun examining whether BCG antibody is of any offer assistance to secure individuals against COVID-19.

\section{Awareness level and preventive measures}

Awareness of an individual's awareness and being able to anticipate his or her behaviour is vital when assessing clinical awareness for pandemics with a highly pathogenic infection. The key to diminishing misfortune of life, personal wounds, and harm from the pandemic condition is widespread public awareness and instruction. Similarly imperative, public authorities and the media $\mathrm{TV}$, radio, and daily papers must be completely arranged to respond viably, dependably, and quickly to large-scale crises. They got to be mindful, in advance, of methods to take after in a crisis that debilitates to paralyze the complete community they serve, and they ought to know how to communicate exact data to the public amid crises. ${ }^{8}$ To stimulate public awareness, brochures, blurbs, recreations, calendars, historical centre shows, open benefit declarations (for print, radio, and TV), and indeed excitement programming ought to be utilized.

One pivotal challenge is how to form a sense of extraordinary measures such as separation, isolate and lock-down. To drive out the myths and give an essential logical understanding of the public wellbeing degree behind the pandemic. A wholeof-society approach to pandemic flu readiness emphasizes the noteworthy parts played not only by the wellbeing divi- sion, but moreover by all other divisions, people, families, and communities, in relieving the impacts of a widespread. ${ }^{11}$ Amid a pandemic, health frameworks will have to give health-care services while attending to the convergence of patients with flu disease. Health-care offices will have to keep up satisfactory triage and contamination control measures to secure health-care specialists, patients, and guests. The Government of India is setting out on a mammoth task to anticipate COVID-19 spread among communities.

\section{Psychological impact of pandemic conditions}

Pandemics are far away from being fair beneficial marvels. They disturb individual and proficient lives seriously and influence individuals and societies on numerous levels. The key methodologies advanced for control of an outbreak of this environment are detention and physical separating both can have critical impacts on life and connections. ${ }^{10}$

Previous works have given away a deep and wide variety of psychosocial possessions on people at the person, area, and in global levels for the period of outbreaks of disease. On a personal level, people are likely to possess dread of falling sickness, feelings of vulnerability, and disgrace. Around $11 \%-30 \%$ of the common public were rather worried about the possibility of contracting the virus during an influenza outbreak. With the closure of schools and industry, negative emotions experienced by individuals are compounded. ${ }^{7}$

During the SARS epidemic, many studies investigate the psychological impact on the non-infected society, providing the important psychiatric morbidities which were found to be associated with younger age and amplified self-blame. The key module learnt from the SARS and MERS epidemics was the impose for early sensitisation of community health experts to the psychological impacts of a pandemic and to provide the psychological health needs of those under medical supervision. ${ }^{2}$

The COVID-19 pandemic causes panic and mental health problems for the public, as experienced beforehand with the Middle-East respiratory syndrome coronavirus (MERS$\mathrm{CoV}$ ). The intervention method that is employed by a variety of health establishment and government bodies in fighting the infection may help in eliminating the threat during the time of uncertainty; however, the multivariate studies done on the previous outbreaks show that they have long-term mental health effects on the population. ${ }^{9}$

\section{Review of literature}

Reviews Objective Findings

Review 1 Awareness, demeanours, The great share of the and practices related to members appeared MERS-CoV among the high levels of concern public in Saudi Arabia. and had utilized preparatory measures. 
Review 2 Stress and mental effect in extreme intense respiratory disorder (SARS) patients amid the 2003 episode

Review 3 Participants' characteristics, clinical parameters, wellbeing behaviours, HL, depression during COVID-19

Review 4 To assess and think about comparative episodes from the past to get it its antagonistic effect on mental wellbeing

Review 5 To study the common public in China to superior get it their levels of mental effect, uneasiness, misery, and push amid the introductory organize of the COVID-19 episode.
Functional impairment is clear within the postrecovery stage

A potential advantage of HL was found in that it can offer assistance to secure the mental wellbeing and HRQoL of individuals with S-COVID-19 amid the widespread.

To provide steps to handle and give a foundation to doctors and healthcare specialists at the time of such episodes to apply psychological first aid

Recognized components related to a lower level of mental effect and way better mental wellbeing status that can be utilized to define mental interventions to progress the mental wellbeing

\section{Research problem}

To control the spread of the illness, the world researcher society came together. In any case, the incompetence of the countries, indeed with the progressed therapeutic sciences and assets, has fizzled to deal with the mental wellbeing perspective among the public, as all endeavours are centred on understanding the study of disease communication, clinical highlights, transmission designs, and administration of COVID-19 pneumonia.

During an irresistible difficult outbreak, it is basic to learn as much as conceivable almost the concerns, information, demeanours, and behaviour of the public. Such data can be significant to the enhancement of communication endeavours by public wellbeing authorities and clinicians. Based on our understanding, most of the investigation related to this episode centres on distinguishing the study of disease transmission and clinical characteristics of infected patients, the genomic characterization of the infection, and challenges for worldwide wellbeing administration. In any case, no investigating articles are looking at the awareness level and mental status of individuals on COVID-19 on the common population in India. This study also involves the causes for the psychological effect of people during this outbreak and also explains the current psychological status of the people which is not discussed in many studies. This may help government offices and healthcare experts in defending the mental pros- perity of the community within the confront of COVID-19 episode development in India and diverse regions of the world.

\section{The objective of the study}

1. To analyse the level of awareness of the individuals about COVID-19

2. To investigate the current psychological status of individuals during the outbreak.

3. To suggest the measures and coping techniques to improve the psychological health of the individual during the pandemic situation.

\section{Research methodology}

The present survey study is based on the essential information collected from 510 of the people over different parts of Tamilnadu in India. Snowball sampling survey technique is used for collecting the data. A cross-sectional overview plan to evaluate the public's awareness and quick psychological status response amid the afflict of COVID-19 by utilizing an online survey. The online overview was, to begin with, spread to the companions and understudies and they were empowered to pass it on to others.

\section{Procedure}

As the Government prescribed the public to minimize the live interaction and confine at domestic, probable respondents were electronically welcomed by existing consider respondents. They completed the surveys through a web overview stage. Data around this study was posted. All respondents gave educated assent. Information collection took put over 20 days (30th March-25th April 2020) after the WHO announced the COVID-19 episode as a public wellbeing crisis of worldwide concern.

\section{Survey development}

The overview comprised socio statistic factors, information and concerns almost COVID-19; prudent measures against COVID-19; the mental affect of the COVID-19 flare-up; and mental wellbeing status.

The socio statistic portion comprises of the age, sex, conjugal status, capability, range of area and occupation. The awareness level of the survey included information around COVID-19 factors included the level of certainty, in conclusion, level of fulfilment of wellbeing data approximately COVID-19, the drift of unused cases and passing, and potential treatment for COVID-19 contamination. Respondents were inquired to show their source of data. Concern around COVID-19 factors included self and other family individuals contracting COVID-19 and the chance of surviving on the off chance that infected. A self-administered survey that has been approved within the Tamilnadu population for deciding the degree of mental effect after the presentation to a public 
wellbeing emergency inside one week of beginning. Mental wellbeing status was measured utilizing the discouragement, uneasiness, stress and boredom of people at home.

\section{Research limitations}

The essential confinement of this study is the self-report by the people. So there are chances for biases within the reports. The study was conducted as it were by the online mode through which as it were people utilizing social media can be analyzed. As a result, might not conduct an imminent think about that would give a concrete finding to support they require for a centred public health activity. There was an oversampling of a specific arrange of peers, driving to choice predisposition. Another impediment is that self-reported levels of mental effect, uneasiness, misery and stretch may not continuously be adjusted with an appraisal by mental health experts. So also, respondents might have given socially desirable reactions in terms of the fulfilment with the wellbeing information received and precautionary measures.

\section{Data Analysis and Interpretation}

\section{Awareness level of individuals and Sources which keep most informed about COVID-19 and its preventive meas- ures}

\section{Interpretation}

From the data collected from 510 respondents, Table I shows the clear data, about $100 \%$ of the individuals are aware of the pandemic situation of COVID-19, about 70 percentage of the people have strongly agreed that they follow the precautious measures to prevent COVID-19, 95 percentage of the participants possess a clear idea about the various symptoms of COVID-19.82 percentage of the people are aware of the contact numbers and the persons to be contacted during the emergency of COVID-19.100 percentage of the people agreed that they and their family strictly follow stay at home and stay safe policy. Figure 2 also shows the awareness level. From Table II it's clear that TV holds the first rank which people says that it keeps them updated and informed about the preventive measures of COVID-19, next Newspaper holds the second rank in informing the people, Friends and social media holds the third place and Government Ads holds the fifth place in keeping the people informed about the information about COVID-19.

\section{Current Psychological Status of People}

\section{Interpretation}

From Table III it's clear that about $49 \%$ of the individual possesses a high level of fear and anxiety about COVID-19 situation. Figure 3 shows the level of fear and anxiety. 54 percentage of the persons conveyed that they are not stressed about the pandemic situation. 37 percentages of participants do exercise as their personal care activity at this time. About
52 percentages of people feel boredom by missing their outdoor activities. $71 \%$ of the people feel adapted to the changes in the normal patterns of living after the breakdown. About 68 percentages of the individuals have changed in their eating and sleeping pattern after the breakdown. $72 \%$ of participants agreed that they experience a change in moods and behaviours after the outbreak.

\section{Socio-demographic and Awareness level of people}

$\mathbf{H}_{\mathbf{1}}$ : There is a significant relationship between the gender and symptoms of COVID-19 awareness of the individual

\begin{tabular}{lccc}
\multicolumn{4}{c}{ Chi-Square Tests } \\
Value & df & $\begin{array}{c}\text { Asymp. Sig. } \\
\text { (2-sided) }\end{array}$ \\
Pearson Chi-Square & $82.362^{\mathrm{a}}$ & 3 & .000 \\
Likelihood Ratio & 60.254 & 3 & .000 \\
Linear-by-Linear Association & 39.707 & 1 & .000 \\
N of Valid Cases & 510 & & \\
\hline
\end{tabular}

${ }^{a_{2}}$ cells $(25.0 \%)$ have expected count less than 5 . The minimum expected count is .66.

Interpretation: Since the value of $\mathrm{P}<0.05$, we reject the null hypothesis. So there exists a significant relationship between the age and awareness of the symptoms

$\mathbf{H}_{2}$ : There is a significant relationship between the location and awareness of the contacts and persons to be contacted during emergencies

\begin{tabular}{lccc}
\multicolumn{4}{c}{ Chi-Square Tests } \\
Value & df & $\begin{array}{c}\text { Asymp. Sig. } \\
\text { (2-sided) }\end{array}$ \\
Pearson Chi-Square & $8.891^{\mathrm{a}}$ & 2 & .012 \\
Likelihood Ratio & 9.443 & 2 & .009 \\
Linear-by-Linear Association & 7.724 & 1 & .005 \\
N of Valid Cases & 510 & & \\
\hline
\end{tabular}

${ }^{\mathrm{a}} \mathrm{O}$ cells $(0.0 \%)$ have expected count less than 5 . The minimum expected count is 23.27 .

Interpretation: Since the value of $\mathrm{P}<0.05$, we reject the null hypothesis. So there exists a significant relationship between the location and awareness of the contact person during this pandemic situation

$\mathbf{H}_{3}$ : There is a significant relationship between the educational qualification and awareness of the symptoms and preventive measures of COVID-19.

\begin{tabular}{lcccc}
\multicolumn{5}{c}{ Chi-Square Tests } \\
& Value & df & Asymp. Sig. (2-sided) \\
Pearson Chi-Square & $25.994^{\text {a }}$ & 4 & .000 \\
Likelihood Ratio & 32.887 & 4 & .000
\end{tabular}


Linear-by-Linear As- $\quad 3.817 \quad 1 \quad .051$ sociation 510

$\mathrm{N}$ of Valid Cases

${ }^{\mathrm{a}} 1$ cells $(10.0 \%)$ have expected count less than 5 . The minimum expected count is 4.90 .

Interpretation: Since the value of $\mathrm{P}<0.05$, we reject the null hypothesis. So there exists a significant relationship between the educational qualification and awareness of the symptoms and preventive measures of COVID- 19 .

\section{Socio-demographic and psychological status}

$\mathbf{H}_{4}$ : There is a significant relationship between the age and level of fear and anxiety of the individual.

\begin{tabular}{lccl}
\multicolumn{4}{c}{ Chi-Square Tests } \\
& Value & df & $\begin{array}{c}\text { Asymp. Sig. } \\
\text { (2-sided) }\end{array}$ \\
Pearson Chi-Square & $80.599^{\mathrm{a}}$ & 9 & .000 \\
Likelihood Ratio & 77.370 & 9 & .000 \\
Linear-by-Linear Association & .342 & 1 & .558 \\
N of Valid Cases & 510 & & \\
\hline
\end{tabular}

a 3 cells $(18.8 \%)$ have expected count less than 5 . The minimum expected count is 1.95 .

Interpretation: Since the value of $\mathrm{P}<0.05$, we reject the null hypothesis. So there exists a significant relationship between the age and level of fear and anxiety of an individual.

\section{Other significant relations found under chi-square tests}

Chi-square Interpretations
value

Education qualifica- $\quad$ o.oo A significant relation betion Vs. Personal tween education qualificare activities cation and personal care activities

Age Vs. Change in 0.56

No significant relation sleeping and eating between age and change in eating and sleeping disorder

Location Vs. Feeling 0.00

A significant relation adapted to the situbetween location and adaption to the current situation

\section{Relationship between Awareness level of people and Psychological status}

The below interpretations are analyzed based on the chisquare test

\begin{tabular}{lcl} 
Factors & $\begin{array}{c}\text { Chi-square } \\
\text { value }\end{array}$ & Interpretations \\
\hline $\begin{array}{l}\text { Precaution aware- } \\
\text { ness Vs. Level of } \\
\text { fear }\end{array}$ & o.oo & $\begin{array}{l}\text { A significant relation be- } \\
\text { tween precaution awareness } \\
\text { and level of fear }\end{array}$ \\
$\begin{array}{l}\text { Symptoms aware- } \\
\text { ness Vs. Level of } \\
\text { fear }\end{array}$ & o.oo & $\begin{array}{l}\text { A significant relation be- } \\
\text { tween symptoms awareness } \\
\text { and level of fear }\end{array}$ \\
$\begin{array}{l}\text { Personal care } \\
\text { activities Vs. Frus- } \\
\text { trated missing } \\
\text { outdoor activities }\end{array}$ & o.oo & $\begin{array}{l}\text { A significant relation be- } \\
\text { tween personal care activi- } \\
\text { ties and frustrated missing } \\
\text { outdoor activities }\end{array}$ \\
$\begin{array}{l}\text { Frequent hearing } \\
\text { of news and up- } \\
\text { dates of cases Vs. } \\
\begin{array}{l}\text { Anxiety and stress } \\
\text { level }\end{array}\end{array}$ & o.oo & $\begin{array}{l}\text { A significant relation be- } \\
\text { tween Frequent hearing of } \\
\text { news and updates of cases }\end{array}$ \\
\hline
\end{tabular}

From the above Table, it's clear that the awareness level also impacts in certain ways the psychological status of people.

Level of Frustration Vs. missing outdoor activities

\begin{tabular}{|c|c|c|}
\hline \multirow{2}{*}{ Level of Frustration } & Pearson Correlation & $0.319^{* *}$ \\
\cline { 2 - 3 } & Sig. (2-tailed) & 0.000 \\
\cline { 2 - 3 } & $\mathrm{N}$ & 510 \\
\hline
\end{tabular}

Interpretation: From the above table, it's understood that correlation is significant at the 0.01 level (2-tailed). It's evident that there is a positive correlation between the level of frustration and missing outdoor activities and we can infer that missing outdoor activities can also be a factor that leads to increase in the level of frustration during this outbreak.

\section{Change in sleep and eating pattern Vs. Time saved}

\begin{tabular}{|l|l|c|}
\hline $\begin{array}{l}\text { Change in sleep and } \\
\text { eating pattern }\end{array}$ & Pearson Correlation & $0.244^{* *}$ \\
\cline { 2 - 3 } & Sig. (2-tailed) & 0.000 \\
\cline { 2 - 3 } & $\mathrm{N}$ & 510 \\
\hline
\end{tabular}

Interpretation: From the above table, it's understood that correlation is significant at the 0.01 level (2-tailed). There is a positive correlation between change in sleep and eating pattern and time saved. Thus we can interpret that change in sleep and eating pattern is one among several factors that may be influenced by time saved during this lockdown.

Other factors analyzed using the correlation analysis are as below 


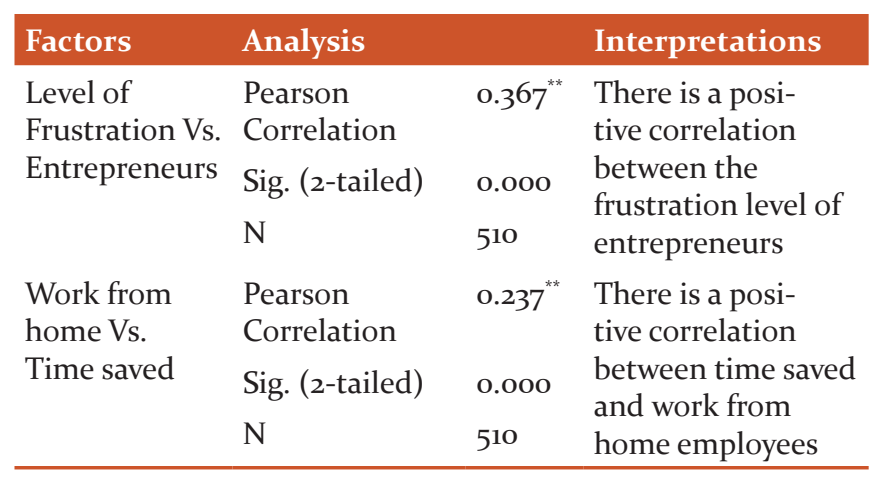

Fear level and depression level across districts

As there is a different number of positive cases in various districts this analysis is made to find the impact of those on people.

$\mathbf{H}_{5}$ : There is a significant relationship between the district and fear and anxiety level of people

\begin{tabular}{|c|c|c|c|c|c|c|}
\hline \multicolumn{7}{|c|}{ ANOVA } \\
\hline & & $\begin{array}{l}\text { Sum of } \\
\text { Squares }\end{array}$ & df & $\begin{array}{c}\text { Mean } \\
\text { Square }\end{array}$ & $\mathbf{F}$ & Sig. \\
\hline \multirow[t]{3}{*}{ Leveloffear } & $\begin{array}{l}\text { Between } \\
\text { Groups }\end{array}$ & 180.957 & 11 & 16.451 & 10.934 & .000 \\
\hline & $\begin{array}{l}\text { Within } \\
\text { Groups }\end{array}$ & 749.247 & 498 & 1.505 & & \\
\hline & Total & 930.204 & 509 & & & \\
\hline \multirow[t]{3}{*}{ Stressed } & $\begin{array}{l}\text { Between } \\
\text { Groups }\end{array}$ & 20.411 & 11 & 1.856 & 8.706 & .000 \\
\hline & $\begin{array}{l}\text { Within } \\
\text { Groups }\end{array}$ & 106.140 & 498 & .213 & & \\
\hline & Total & 126.551 & 509 & & & \\
\hline
\end{tabular}

Interpretation: From the above, it shows that there is a significant relationship between the districts of people in which live and their level of fear and anxiety on COVID-19.

\section{DISCUSSION}

In the statistical analysis, the maximum of the people belongs to the age category between $21-30$ years (60\%). 55\% of the participants in the survey are male. $51.6 \%$ of the respondents have completed their UG degree. $40 \%$ of the participants are from the urban area. $32 \%$ of the participants belong to the Coimbatore district. $45 \%$ of the participants were private employees who work in various sectors. 55\% of the participants have married $.100 \%$ of the participants agreed that they are aware of the pandemic situation and they also follow the stay-home policy. $71 \%$ of the participants are aware of the preventive measures. $48 \%$ of the participants are with high fear and anxiety because of this pandemic situation in India. $42.5 \%$ of the participants were neither feeling difficult nor easy for work from the home condition, which is taking place in many organizations now in India. $42 \%$ of the entrepreneurs feel frustrated on thinking about their company's future development after this pandemic situation. $74 \%$ of the participants felt that in many things the time saved during this lockdown. $52 \%$ of the participants feel boredom and stressed because of missing their outdoor activities. $68 \%$ of the participants have a change in their sleeping and eating pattern after this lockdown. $72 \%$ of the participants feel a change of mood and behaviour after the outbreak. There is a positive correlation between the level of frustration and missing outdoor activities. That there is a positive correlation between change in sleep and eating pattern and time saved. There is a significant relationship between the districts of people in which live and their level of fear and anxiety on COVID-19. Our socio-demographic data propose that males suffered a slightly greater than females psychological impact of the epidemic also higher levels of stress, anxiety, and depression.

\section{SUGGESTIONS}

From the findings it is evident that most of the participants are aware of the current pandemic circumstance in India conjointly it appears that most extreme of the participants are with high fear almost this circumstance conjointly they have a feel of discouragement and pushed additionally a sign of boredom by lost their outdoor exercises which can affect well being of the person. The individuals ought to be given more measures to avoid fear and uneasiness almost this circumstance. recommend that about the introductory mental reactions of the common public from 18 March to 27 April 2020, 44 days into the country's flare-up of COVID-19 and one day after WHO announced public wellbeing crisis of worldwide concern, $53.8 \%$ of respondents evaluated the mental effect of the episode as direct; $17 \%$ of respondents detailed directly to serious depressive side effects; $48 \%$ detailed high fear and extreme stress levels. $72 \%$ felt a change in mood and behaviour. Health specialists need to distinguish high-risk groups based on socio-demographic data for early mental interventions. People who are updated about daily cases feel depressed so people can be asked to minimize watching, reading or listening to news about COVID-19 that causes them to feel anxious or distressed. ${ }^{13}$ As youthful individuals are more responsive towards shrewd phone applications, healthcare specialists may improve consider giving online or keen phone-based psycho instruction and mental mediations to diminish the hazard of infection transmission. Online stages may moreover give a back organize for those individuals investing most of their time at domestic amid the epidemic. The government of India and Tamilnadu state government introduced a lot of awareness programs for raising awareness level among the people. Various advertisements, cam- 
paigns like break the chain, social distancing and all has impacted a lot on creating awareness and regulating the widespread of this epidemic However as most of the members are feared about this circumstance Government and wellbeing specialists have to give precise health information during the epidemic to decrease the effect of rumours. People who are experiencing mood swings and depression are to be advised to stay connected to friends and families through social media or phone. The persons who work from home have a change in the pattern so the organisations should keep them stress-free through online team games etc. The entrepreneurs also projected that they worry about their company development. They should be advised with measures to overcome risks in their field and various alternative ways to develop their company. The prudent measures embraced to anticipate the spread of COVID-19 may have defensive mental impacts during the early stage of the epidemic.

We emphatically recommend that extraordinary care is to be taken in provincial regions where individuals have low access to the internet and other technological measures by giving medical information through announcements utilizing loudspeakers. Text-messaging stages may well be utilized to assist individuals to adapt with mental wellbeing challenges evoked by COVID-19. Because texts are also conveyed through individuals' gadgets, they are simple to provide for many people at once utilizing computerized text-messaging platforms. Text-messaging intercessions have illustrated adequacy in behavioural wellbeing promotion and disease management.

\section{CONCLUSION}

During the introductory stage of COVID-19 episode in Tamilnadu, the results are relative to the current COVID-19 widespread; they pick up to get to mindfulness level, fear, uneasiness, passionate trouble, as the affected people are seen as a minority and private from the rest of the population. Particular up-to-date and exact wellbeing data and certain prudent measures were related with a lower mental effect of the flare-up and lower levels of stretch, uneasiness, and misery. ${ }^{12}$ The mediation measures that are utilized by different wellbeing specialists and government bodies in combating the contamination may offer assistance in disposing of the danger amid the time of vulnerability; in any case, the multivariate thinks about done on the past flare-ups appear that they have long-term cognitive and mental wellbeing impacts on the population. It is imperative the mental wellbeing well-being of the population and takes proactive steps to play down its inconvenient impacts amid the COVID-19 pandemic.

\section{ACKNOWLEDGEMENT}

Our sincere thanks and grateful to all the authors, Ministry of Health - Government of India whose articles/journals/reports and data are cited and included in references to this manuscript. And also we wish to thank the persons who participated in this survey.

Conflict of interest: The authors declare that there is no conflict of interest.

Funding compliance: This study doesn't involve any funding from funding resources.

Compliance with Ethical Standards: All procedures performed in this study involving the participants were by the ethical standards of the institutional research committee and with ethical standards. And also their acceptance for taking part in the survey is collected.

\section{REFERENCES}

1. Bao Y, Sun Y, Meng S, Shi J, Lu L. 2019-nCoV epidemic: address mental health care to empower society. The Lancet. 2020; 395(10224):e37-e38.

2. Brooks S, Webster R, Smith L, Woodland L, Wessely S, Greenberg $\mathrm{N}$ et al. The psychological impact of quarantine and how to reduce it: A rapid review of the evidence. The Lancet. 2020; 395(10227):912-920.

3. Hoang C. Nguyen, $\mathrm{N}$ et al. People with suspected COVID-19 symptoms were more likely depressed and had the lower healthrelated quality of life: the potential benefit of health literacy, J. Clin. Med. 2020, 9(4), 965. Doi: 10.3390/jcm9040965.

4. Balkhy H, Abolfotouh M, Al-Hathlool R, Al-Jumah M. Awareness, attitudes, and practices related to the swine influenza pandemic among the Saudi public. BMC Infectious Diseases. 2010; $10(1)$.

5. Leung G. The impact of community psychological responses on outbreak control for severe acute respiratory syndrome in Hong Kong. Journal of Epidemiology \& Community Health. 2003; 57(11):857-863.

6. Nishiura, H, (Jan 2020). The extent of transmission of a novel coronavirus in Wuhan, China. J. Clin. Med. 2020; 9: 330. https://doi.org/10.3390/jcm9020330.

7. Robertson E, Hershenfield K, Grace S, Stewart D. The psychosocial effects of being quarantined following exposure to SARS: a qualitative study of Toronto health care workers. The Canadian Journal of Psychiatry. 2004; 49(6):403-407.

8. Siew E Chua. Stress and psychological impact on SARS patients during the outbreak. Can J Psychiatry.2004; 49(6).

9. Shah K, Kamrai D, Mekala H. Focus on mental health during the coronavirus (COVID-19) pandemic: applying learnings from the past outbreaks. Cureus.2020; 12(3): e7405.

10. Sim, K. Psychosocial and coping responses within the community health care setting towards a national outbreak of an infectious disease. J. Psychosom.2020; Res. 2010, 68, 195-202.

11. Thompson, R.N. Novel coronavirus outbreak in Wuhan, China, intense surveillance is vital for preventing sustained transmission in new locations. J. Clin. Med. 2020; 9, 498. https://doi. org/10.3390/jcm9020498.

12. Wang C, Pan R, Wan X, Tan Y, Xu L, Ho C et al. Immediate Psychological Responses and Associated Factors during the Initial 
Stage of the 2019 Coronavirus Disease (COVID-19) Epidemic among the General Population in China. International Journal of Environmental Research and Public Health. 2020; 17(5):1729.

13. Xiang, Y.-T. Timely mental health care for the 2019 novel coronavirus outbreak is urgently needed. Lancet Psychiatry 2020; 7 , 228-229. https://doi.org/10.1016/S01406736 (20)30185-9.

14. Total number of cases in India [Internet]. [Cited 27 May 2020]. Available from: https://www.timesofindia.indiatimes.com/india/

Table I: Awareness level of individuals

\begin{tabular}{|c|c|c|}
\hline Factors & Awareness level & Percentage (\%) \\
\hline \multirow{2}{*}{$\begin{array}{l}\text { Aware of the pandemic } \\
\text { situation of COVID-19 }\end{array}$} & Yes & 100 \\
\hline & No & o \\
\hline \multirow{5}{*}{$\begin{array}{l}\text { Follow the precautious } \\
\text { measures to prevent } \\
\text { COVID-19 }\end{array}$} & Strongly Agree & 70 \\
\hline & Agree & 30 \\
\hline & Neutral & o \\
\hline & Disagree & o \\
\hline & Strongly Disagree & o \\
\hline \multirow{2}{*}{$\begin{array}{l}\text { Clear idea about the } \\
\text { symptoms of COV- } \\
\text { ID-19 }\end{array}$} & Yes & 95 \\
\hline & No & 5 \\
\hline \multirow{2}{*}{$\begin{array}{l}\text { Awareness of the } \\
\text { contact numbers and } \\
\text { responsible persons }\end{array}$} & Yes & 82 \\
\hline & No & 18 \\
\hline \multirow{2}{*}{$\begin{array}{l}\text { Strictly follow stay at } \\
\text { home and stay safe } \\
\text { policy }\end{array}$} & Yes & 100 \\
\hline & No & o \\
\hline
\end{tabular}

\section{Table II: Rank of informing sources}

\begin{tabular}{lcc} 
Sources & Mean & Rank \\
TV & 2.38 & 1 \\
Newspaper & 3.09 & 2 \\
Friends & 3.15 & 3 \\
Social Media & 3.15 & 3 \\
Government Ads & 3.19 & 5 \\
\hline
\end{tabular}

Table III: Psychological Status of People

$\begin{array}{llc}\text { Factors } & \text { Awareness level } & \text { Percentage (\%) } \\ \begin{array}{l}\text { Level of fear and } \\ \text { anxiety possessed } \\ \text { about COVID-19 }\end{array} & \text { Very high } & 19 \\ & \text { Migh } & 49 \\ & \text { No fear } & 18 \\ \begin{array}{l}\text { Feeling stressed } \\ \text { on thinking about } \\ \text { COVID-19 }\end{array} & \text { Nes } & 14 \\ \end{array}$

coronavirus-india-live-news-updates-total-number-of-covidcases-in-india-count-state-wise-death-toll/liveblog/75000767. cms.

15. Coronavirus Disease (COVID-19) - events as they happen [Internet]. Who.int. 2020 [cited 28 April 2020]. Available from: https://www.who.int/emergencies/diseases/novel-coronavirus-2019/events-as-they-happen

\section{Factors}

Personal self-care activities that indi-

vidual do at this time Reading books

Exercise$$
\text { . }
$$

$\begin{array}{llr} & \text { Yoga } & 4 \\ & \begin{array}{l}\text { Playing indoor } \\ \text { games }\end{array} & 3 \\ & \text { Others } & \\ & & \\ \begin{array}{l}\text { Missing the outdoor } \\ \text { activity during this } \\ \text { breakdown makes } \\ \text { feel frustrated and }\end{array} & \text { No } & 48 \\ \text { bordom } & \end{array}$

37

23

4

3

\section{Awareness level Percentage (\%)}

35

52

48

boredom

Feeling adapted to

the changes in the normal patterns of

living

Yes

71

No 22

Changes in sleeping Yes $\quad 68$

or eating patterns

after this outbreak

Moods swings and

change of behaviours

after breakdown

No

32

Strongly Agree $\quad 72$

Agree 20

Neutral 8

Disagree 0

Strongly Disagree o

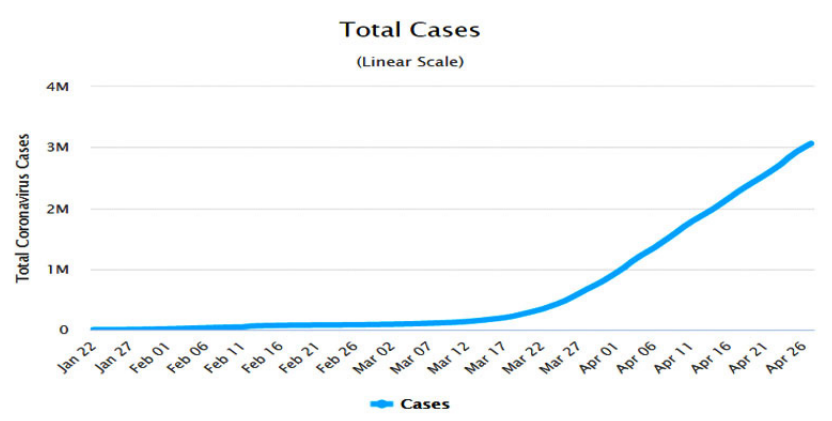

Figure 1: Current case levels, Source: World meter. 


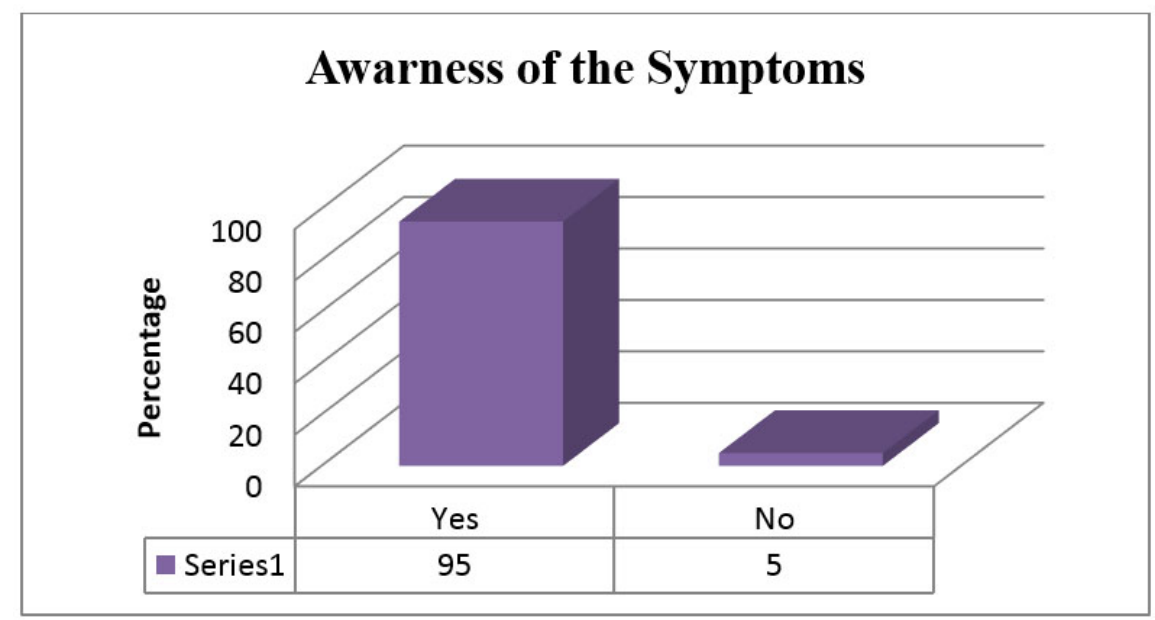

Figure 2: Awareness level of individuals on the symptoms of COVID-19.

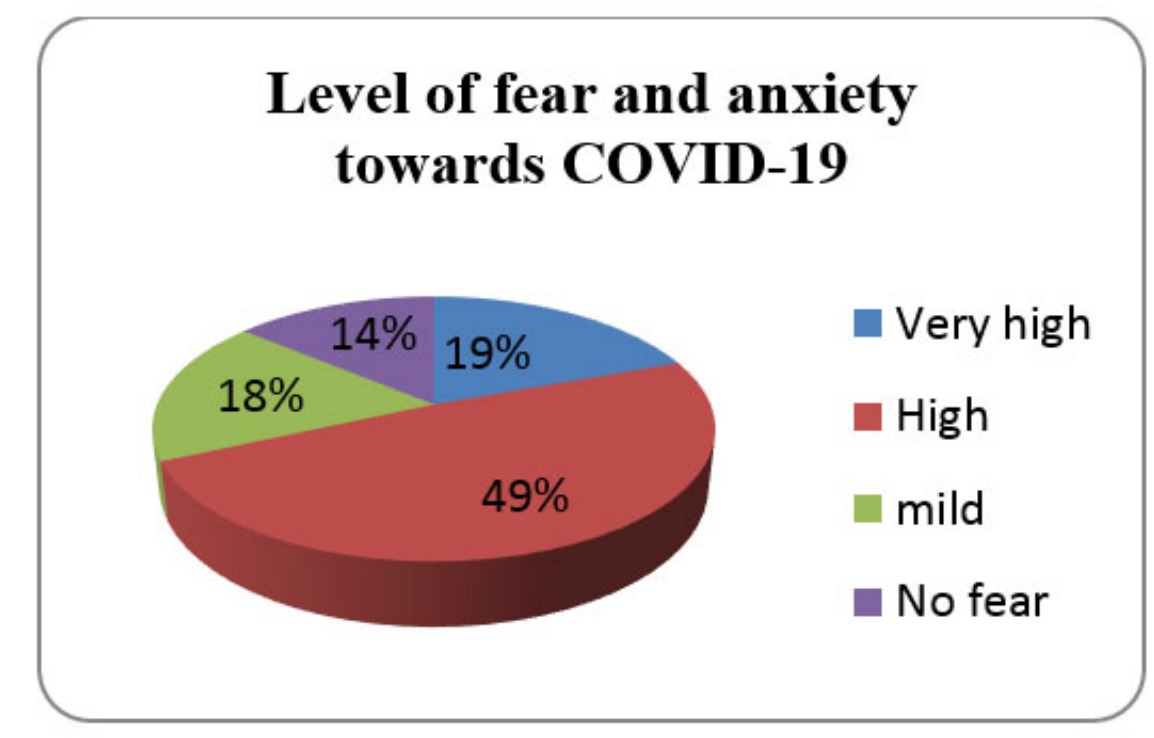

Figure 3: Level of fear and anxiety towards COVID-19. 